\title{
A Psychometric Review of Instruments for Social Justice and Advocacy Attitudes
}

\author{
Alexander W. Fietzer \\ Department of Educational Foundations and Counseling, Hunter College of the City \\ University of New York
}

\section{Joseph Ponterotto}

Department of Counseling and Counseling Psychology, Fordham University.

\begin{abstract}
The authors review instruments measuring social justice and advocacy. A review of the literature revealed four scales that met inclusion criteria. The Activism Orientation Scale (AOS), Social Issues Advocacy Scale (SIAS), Social Issues Questionnaire (SIQ), and the Social Justice Scale (SJS) are evaluated in terms of item development, psychometric properties, and practical utility. Each instrument was evaluated on item development, reliability (internal consistency, test-retest reliability), and evidence for validity (in terms of content, internal structure, and relationship with other variables). In general, all of the instruments lacked adequate levels of psychometric evidence in test-retest reliability, validation on more diverse samples, and use of more robust confirmatory methods (e.g., confirmatory factor analysis). Recommendations and future directions for research are discussed.
\end{abstract}

Keywords: social justice, advocacy, research instruments, validity and reliability 
Social justice and advocacy enjoyed a renewed interest among counselors and psychologists over the past fifteen years. Doctoral students now demand more social justice training from their graduate programs (Beer, Spanierman, Green, \& Todd, 2012), doctoral curricula increasingly reflect social justice content (Pieterse, Evans, Risner-Butner, Collins, \& Mason, 2009), and professional organizations continue to incorporate advocacy competencies into their professional identities (Chang, Crethar, \& Ratts, 2010; Speight \& Vera, 2008). Further, research has demonstrated the psychological and physical harm resulting from issues of discrimination (Almeida, Johnson, Corliss, Molnar, \& Azrael, 2009; Barnes et al., 2008; Hunte \& Williams, 2009; Pascoe \& Richman, 2009). Thus, there is a need to identify common factors that promote social justice and advocacy among individuals.

Previous reviews of social justice literature have identified the need for more research on the development of common factors of social justice. Speight and Vera (2008) noted that further research is required to understand the development of social justice allies as well as training and program development in advocacy and social justice practice among students in counseling psychology and other professions. Some research has already begun towards this process. For instance, in a phenomenological study, Broido (2000) identified nine types of learning among students who became social justice allies. Nilsson and Schmidt (2005) conducted an exploratory investigation into the factors influencing social justice engagement among 134 graduate students and found that only political interest and desire to be engaged in social justice predicted actual engagement in social justice behavior. However, there remains a paucity of studies exploring engagement in social justice and advocacy. Thus, the present article endeavors to survey the literature and critically review instruments for measuring social justice and advocacy to identify specific instruments which might further research and practice.

By critically examining these instruments, practitioners maintaining a social justice agenda will have access to tools which can identify allies, stimulate introspective approaches to self-knowledge about social justice, and identify new ways to encourage engagement in advocacy in others. Researchers would be able to identify psychometrically sound instruments in social justice, leading to more complex theoretical development about social justice engagement, a better understanding of the factors contributing to social justice, and a way to demonstrate how engagement in advocacy and social justice directly benefit communities.

\section{Defining Social Justice and Advocacy}

Multiple definitions exist for social justice, although most emphasize changing or transforming inequality among underprivileged subgroups within society to be more equitable, often at an institutional or systemic level. Definitions frequently differ in emphasis on outcome or process (Speight \& Vera, 2008). Concepts such as individual justice (whereby all individuals have access to equal rights) and distributive justice 
(whereby opportunities, resources, and power are equitably distributed) illustrate definitions which preference outcome of rewards (Rawls, 1971). In contrast, a communitarian model of justice targets the decision-making process of how resources are distributed as key to social justice.

Other definitions incorporate theoretical constructs from other disciplines into social justice. Goodman et al. (2004) overlay an ecological model onto the definition of social justice. They assert that micro (individual, family), meso (communities, organizations), and macro (social structures, ideologies, policies) levels capture the pervasive nature of oppression and highlight the need for pressure/intervention at all levels of a system to impose change. Crethar et al. (2008) incorporate harmony into the definition, defining it as individual or group agency benefitting society as a whole without restricting the equity, access, or participation of others. Most definitions stated that social justice necessarily seeks to change the status of groups marginalized within a society due to different identity statuses, including but not limited to race, ethnicity, gender, sexual orientation, gender, religion, age, ability, and socioeconomic status (e.g., Constantine, Hage, Kindaichi, \& Bryant, 2007; Fouad, Gerstein, \& Toporek, 2006).

Advocacy has more convergence than social justice among author definitions, which share the common theme of proactivity in changing institutional policies to be more equitable for individuals. As with social justice, some authors (e.g., Lewis, Arnold, House, \& Toporek, 2002) view advocacy as occurring within three different levels of an ecological model: the individual level, the policy/institutional level, and the training or educational level. In the Advocacy Competencies, Lewis et al. (2002) defined advocacy across two dimensions: level of intervention (client/student, school/community, public arena) and the extent of client involvement (acting on behalf of a client, acting with a client). The resulting six domains are a taxonomy encompassing the potential ways to be an advocate. For instance, working with community elders to organize a trip to the state senate to advocate for a new health center would be classified as community collaboration (Toporek, Lewis, \& Crethar, 2009).

For the present article, we defined social justice as engagement in the active transformation of individual actions, communities, and institutions, to be more equitable for groups marginalized due to their disadvantaged status in society to create a more harmonious system. We defined advocacy as action which encourages a change in the way that an individual, community, or institution makes a decision about the treatment of a disadvantaged group in society.

\section{Reflexivity}

The two authors of this article are counseling psychologists engaged in multicultural and social-justice oriented research with adolescents and adults, and both are practicing clinicians focusing on a culturally diverse clientele. The authors are Caucasian men. The senior author is in his 30s and is third generation German American raised in the 
Midwest and Southeast US; while the second author is in his 50s and is first generation Italian American raised in the Bronx, NY. Both authors actively process their own privilege and developed a social justice orientation to practice and research through professional training, experiential learning, and significant role models and mentors in their lives. In terms of social justice and advocacy assessment, we are interested in examining barriers that prevent student engagement in activist activities and determining ways to circumvent those barriers. Further, assessment could determine the current location within the Advocacy Competency domains (Lewis et al., 2002) of a student eager to initiate advocacy activities but unsure how it aligns with his or her interests or long-term goals.

\section{Criteria Used to Define Acceptable Test Development Practices}

We used the Standards for Educational and Psychological Testing (hereafter known as Standards: American Educational Research Association [AERA], American Psychological Association [APA], National Council on Measurement in Education [NCME], 1999) as the foundational criteria to define acceptable test development practice and supplemented the Standards with studies that provided empirical evidence regarding advances in specific fields of test construction. We supplemented the Standards with a review of empirical studies for best practices in item development (Gehlbach \& Brinkworth, 2011). These include avoiding reverse-scored items and having respondents respond to agreedisagree items, using Likert scales consisting of either five or seven points dependent upon the construct in question, ensure that each component of each item applies to all participants, and labeling each response anchor with a construct-specific label.

The psychometric properties of a measure can be evaluated using either classical test theory or more contemporary approaches such as generalizability theory or itemresponse theory (Furr \& Bacharach, 2008). The tests reviewed in this paper used classical test theory to establish their psychometric properties so more contemporary approaches will not be discussed here. In the Standards (AERA, APA, NCME, 1999), classical test theory is divided into evidence for reliability and evidence for validity. Evidence for reliability is established for each sample and can be evaluated based on differences over time (test-retest reliability), differences in test content (alternate forms reliability), differences due to the internal structure of a test (internal consistency), and differences due to subjective observation (interrater reliability). To gauge whether internal consistency coefficients were adequate, we used Ponterotto and Ruckdeschel's (2007) reliability matrix for internal consistency.

Evidence for the validity of a test can be evaluated based on a test's content, internal structure, relationship with other variables, response processes of examinees, and the consequences of using the measure (AERA, APA, NCME, 1999). As with item development, we supplemented these guidelines with empirical studies that examined decision-making processes when analyzing the internal structure of the test. For determining the factor structure in exploratory phases of analysis, Ruscio and Roche 
(2012) found that parallel analysis was the most effective method (compared to analysis of eigenvalues and scree plots, the Minimum Average Potential procedure, Akaike's Information Criterion, and Bayes Information Criterion). For method of extraction, we used the recommendations of Fabrigar, Wegener, MacCallum, and Strahan (1999). For guidelines on sufficient sample size in factor analysis, we used the recommendations from MacCallum, Widaman, Zhang, and Hong's (1999) study. For confirmatory factor analysis (CFA), we compared fit measures in the current instruments with the means of fit indices reported in 194 CFA studies by Jackson, Gillaspy, and Purc-Stephenson (2009), using the means and standard deviations from their study as a normative sample for comparison.

\section{Method}

To review the literature, the first author searched six databases-Academic Search Complete, ERIC, Mental Measurements Yearbook with Tests in Print, PsychARTICLES, PsychINFO, and Social Work Abstracts - in peer-reviewed journals from the years 2000 to 2012. We chose the year 2000 as a cut-off because it was the first year after the Standards (AERA, APA, NCME, 1999) was published, thus presumably being the earliest year that tests meeting Standards criteria would be published. In addition, although there has been a steady publication of articles about social justice over the past century, there appears to be a renewed interest in the topic beginning at the turn of the millennium. A PsychINFO search provides evidence of this trend, as a search of the term social justice for the years 1879 to 1999 yields 514 results, while a search of the same term between the years 2000 and 2012 yields 4,737 results.

The initial search used the terms social justice and scale and yielded 266 results. The process was repeated replacing the term social justice with advocacy, social action, or activism and using PsychINFO to minimize the number of unrelated hits to a more manageable degree. This produced 153 results, 14 results, and 54 results respectively. Abstracts of each article were examined to determine whether a study may have used an instrument which measured either social justice or advocacy based on the above definitions. Any doubt was cause to obtain the article and inspect the operationalization of the instrument to compare it to the working definition.

Inclusion criteria were that the instrument (1) must be published in English and (2) had reported psychometric properties. Exclusion criteria were based upon identifying common factors among social justice and advocacy behavior in future research. Thus, we excluded instruments focusing on particular groups (e.g., women) or components (e.g., Christian-based social justice) of social justice and advocacy, as it could be argued that people who are interested in advocating for one disadvantaged group may not be the same as those advocating for all disadvantaged groups. Although clearly more research is required to determine whether this is the case, it seems that inclusion of measures broadly defining social justice provides a useful starting point. Finally, dissertations were excluded because they were more limited in the scale of their 
development and lacked peer masked review. For instance, Dean's (2009) Social Justice Advocacy Scale used an inadequate number of participants (100) for its EFA and provided no cross validation or CFA procedures as evidence of its validity.

Our resultant review produced four instruments that met the criteria: the Activism Orientation Scale (AOS: Corning \& Myers, 2002), the Social Issues Advocacy Scale (SIAS: Nilsson, Marzolek, Linnemayer, Bahner, \& Misialek, 2011), the Social Issues Questionnaire (SIQ: Miller et al., 2009), and the Social Justice Scale (SJS: TorresHarding, Siers, \& Olson, 2012). Each of the four major instruments is reviewed in terms of its operationalization of social justice, its item development, currently known psychometric properties, and the format. The review ends with a critique of each instrument. We finish with an assessment of the literature in social justice in general.

\section{The Activism Orientation Scale}

The Activism Orientation Scale (AOS; Corning \& Myers, 2002) is a 35-item scale that measures an individual's propensity to engage in social action from a general (rather than issue-specific) perspective across a wide range of behaviors. Stemming from political psychology, the AOS consists of two subscales rated on a Likert scale from 0 (extremely unlikely) to 3 (extremely likely). The Conventional Activism scale contains 28 items (sample item: How likely is it that you will display a poster or bumper sticker with a political message?) and the High-Risk Activism scale contains seven items (sample item: How likely is it that you will engage in an illegal act as part of a political protest?). Either the total scale or individual subscale scores can be used.

The authors defined an activist orientation as "an individual's developed, relatively stable, yet changeable orientation to engage in various collective, social-political, problem-solving behaviors spanning a range from low-risk, passive, and institutionalized acts to high-risk, active, unconventional behaviors" (p. 704). They further elaborated that "the behavior must intend to address some perceived problem, injustice, or disadvantage affecting the collective" (p. 707). The AOS fulfills a niche in social justice and advocacy instruments in that it measures activism from a general perspective (as opposed to an issue-specific perspective such as women's rights) as informed by empirical research in the field of social activism. Corning and Myers (2002) conceptualize activism as an attitude developed through a socialization process that predicts behaviors in social action (e.g., engagement in political rallies) and that remains relatively stable over time. Thus, one's activist attitudes have the capacity to change (and thus seem conceptually similar to a characteristic adaptation as defined by McAdams \& Pals, 2006).

Item Development. Forty items were developed based on the definition of activist orientation stated previously. Items were designed to include (1) behaviors spanning the range from low-risk and conventional behaviors to high-risk and unconventional 
behaviors, (2) behaviors that assessed interpersonal and organizational ties among activists, and (3) behaviors assessing resource accumulation (such as fundraising). Four judges with expertise in social action practice or research quantitatively rated the items relative to the construct and provided qualitative feedback about each item. Items scored low by the judges were revised for clarity.

Psychometric Properties. Evidence of the construct validity of the AOS derived from three studies. In the first, Corning and Myers (2002) examined the internal structure of the AOS using principal axis factoring with oblique rotation on data from a sample of 296 undergraduates from a university in the Midwest United States. Using a scree plot, they examined alternative solutions before arriving at a two factor solution. Factor one explained $83.4 \%$ of the variance and factor two explained $16.6 \%$ of the variance. The factors correlated at .54, suggesting they were non-redundant factors. Three items were eliminated due to low factor loadings. A second study of 224 graduate and undergraduate students reported in Corning and Myers found that the overall AOS and Conventional subscale correlated moderately with measures of collective relative deprivation (perceptions that one's group is disadvantaged relative to other groups) and with internal locus of political control, while the High-Risk subscale correlated with moderately with political control, and all scales correlated strongly with a measure of collective behavior for women. This correlation differed as predicted with women having a higher correlation (.69) than men (.28). Evidence for discriminant validity was strong in that the AOS and its subscales did not correlate with measures of personal efficacy or interpersonal control, although none of the scales correlated with a measure of egoistic relative deprivation (perception that one is personally disadvantaged compared to others) as predicted. Evidence for criterion validity was robust as mean total AOS scores differed among groups (e.g., student labor union attendees, students attending a communications course) as predicted (Corning \& Myers). A third study (which used a rational approach to reduce the number of items to 20 on the AOS) found that the Conventional subscale correlated with positive affect, self-actualization, meaning in life, hope, and agency in measures of subjective and eudaimonic well-being (Klar \& Kasser, 2009).

Reliability of the AOS and its subscales is robust in terms of internal consistency. Across studies coefficient alphas for the total AOS and its subscales consistently fell in the excellent range (Ponterotto \& Ruckdeschel, 2007), with scores ranging from a low of .87 to a high of .97 for the total scale (see Table 1 ). Test-retest reliability was not reported or assessed.

\section{Social Issues Advocacy Scale}

The Social Issues Advocacy Scale (SIAS; Nilsson et al., 2011) is a 21-item scale that measures social justice advocacy. The SIAS was derived from the counseling psychology literature on social justice. Items are rated on a Likert-type scale from 1 
(strongly disagree) to 5 (strongly agree). There are four subscales: the Political and Social Advocacy subscale consists of eight items (sample item: I participate in demonstrations or rallies about social issues that are important to my profession), the Political Awareness subscale has six items (sample item: I keep track of important bills/legislative issues that are being debated in Congress that affect my profession), the Social Issues Awareness subscale has four items (sample item: State and federal policies affect individuals' access to social services), and the Confronting Discrimination subscale has three items (sample item: I am professionally responsible to confront colleagues who display signs of discrimination toward the elderly). Nilsson et al. define social justice as "the fundamental valuing of fairness and equity in resources, rights, and treatment for marginalized individuals and groups of people who do not share equal power in society" (Constantine et al., 2007, p. 24). They define advocacy as "action that is directed toward changing or transforming the process by which public decisions are made, thereby affecting the political, social, and economic contexts that influence peoples' lives (p. 259)."

Nilsson et al. (2011) derived the scale from the social justice tradition within counseling psychology, linking activism with the multicultural counseling competency movement. The authors noted that social justice and advocacy are critical in redressing unjust disparities in the institutions of education and health care. The SIAS further fulfills a gap among survey instruments in that it is brief, displays robust psychometric evidence, and can be applied to several different academic fields while still assessing multiple domains of social justice advocacy, including awareness and behavior.

Item Development. Items were created after a thorough literature search involving multiple different synonyms for social justice and advocacy in several different fields. This yielded 96 initial items which belonged to three general areas: (1) personal social justice advocacy (i.e., personal attitudes which support the equality and inclusion of all individuals), (2) professional advocacy (i.e., professional attitudes which support the equality and inclusion of all individuals), and (3) legislative advocacy (i.e., behaviors within the political sphere such as voting which support the equality and inclusion of all individuals). An expert panel of five graduate students and three faculty members interested in social justice or scale development reviewed the items, revising an unspecified number.

Psychometric Properties. Evidence for the internal structure of the SIAS derives from two studies (Nilsson et al., 2011). In the first study, the authors performed principal components analysis (PCA) on the data from 278 participants, $78 \%$ of which were women and $93 \%$ of which were students. Item skew and the use of five anchors on the Likert scale caused Nilsson et al. to treat the items as categorical and thus, they used polychoric (rather than Pearson) inter-item correlations The items were subjected to an iterative exploratory process (O'Connor, 2000) using PCA with oblique rotation and parallel analysis to determine factor structure. After solutions of ten factors and five factors, this process was repeated until they achieved a solution of four factors 
comprised of 21 items. They reported a Kaiser-Meyer-Olkin statistic of .88 and results explained $71.4 \%$ of the variance. As predicted, subscales of the SIAS were moderately correlated, ranging from .19 to .62 .

In the second study, the authors sought confirmatory evidence for the internal structure of the SIAS on a sample of 509 undergraduate and graduate students by running the same 21 items through the same analysis (PCA with oblique rotation, forcing four factors). They found the same loading pattern for all items, with the Political and Social Attitudes subscale accounting for $35.9 \%$ of the variance, the Political Awareness subscale for $31.5 \%$, the Social Issues Awareness subscale for $20.3 \%$, and the Confronting Discrimination subscale $15.6 \%$. Correlations between subscales ranged from .14 to .63. Evidence for the relationship between the SIAS, its subscales, and other variables was robust. Specifically, all SIAS subscales correlated moderately with measures of political interest, empathic feeling and expression, actual political activism, and desired political activism. The subscales did not correlate with measures of selfesteem or life satisfaction, demonstrating evidence of discriminant validity.

There is strong evidence of the internal consistency reliability of the SIAS and its subscales. Due to the use of polychoric correlations, coefficient theta was used to measure internal consistency rather than coefficient alpha, although both are interpreted in the same way. These theta coefficients fell in the excellent range for all subscales and for the total SIAS (see Table 1: Ponterotto \& Ruckdeschel, 2007). No evidence for test-retest reliability was provided.

\section{Social Issues Questionnaire}

The Social Issues Questionnaire (SIQ; Miller et al., 2009) is a 52-item scale that measures interest in social justice from a vocational counseling psychology perspective. The SIQ is a modification of social-cognitive career theory (SCCT; Lent, Brown, \& Hackett, 1994) that hypothesizes an interactive model for the underlying psychological processes that lead to interest in social justice. The SIQ consists of six separate scales: the Social Justice Self-Efficacy scale contains 20 items composing four separate subscales (sample item: How much confidence do you have in your ability to actively support needs of marginalized social groups); the Social Justice Outcome Expectations scale has ten items (sample item: Engaging in social justice activities would likely allow me to reduce oppression of certain groups); the Social Justice Interest scale nine items (sample item: How much interest do you have in going on a weeklong service or work project); the Social Justice Commitment scale four items (sample item: In the future, I intend to engage in social justice activities); the Social Justice Supports scale five items (sample item: If you were to engage in social justice activities, how likely would you be to feel support for this decision from important people in your life); and the Social Justice Barriers scale has four items (sample item: If you were to engage in social justice activities, how likely would you be to worry that getting involved would require 
too much time or energy). All scales are rated on a Likert-type scale ranging from zero to 9.

Miller et al. (2009) defined social justice advocacy as incorporating several concepts, including the alleviation of disparity and redistribution of resources, the full and equal participation of all groups in a society, minimization of health disparities between groups, and social action to create these changes at institutional and societal levels. The authors posited that interest and commitment to social justice occurs through a social cognitive framework and developed two models derived from the SCCT literature: an indirect effects model and a direct effects model. Both models are identical in their predictions except that in the direct effects model, Social Justice Supports and Barriers are correlated and have direct effects on Social Justice Self-Efficacy and Social Justice Commitment whereas in the indirect effects model, Supports and Barriers also have an indirect effect on Social Justice Commitment as mediated through Social Justice SelfEfficacy.

Item Development. Miller et al. (2009) reported that items were developed by adapting existing items from instruments measuring mathematical interests found in Lent et al. (2001). Items were revised based on a review of the social justice literature in counseling psychology (e.g., Toporek et al., 2006; Vera \& Speight, 2003) and by review of a panel of experts in social justice and SCCT. This resulted in the elimination of five items from the Social Justice Self-Efficacy scale and the revision of numerous items from other scales for wording, specificity of content, likelihood of producing sufficient variance among responses, and consistency with SCCT.

Psychometric Properties. Evidence for the internal structure of the SIQ comes from two published studies (Miller et al., 2009; Miller \& Sendrowitz, 2011) and an unpublished manuscript (Miller et al., 2007). No exploratory methods were reported to identify the factor structure; instead, items were developed theoretically and subjected to CFA. The overall SIQ was subjected to CFAs on two different samples of 274 college students and 229 counseling psychology doctoral students. The authors used covariance and asymptotic covariance matrices and Satorra-Bentler scaled chi-square for estimation with three scales (Self-Efficacy, Outcome Expectations, and Interests) using item parcels while the remaining scales used individual items. The CFAs supported the sixfactor measurement model hypothesized by the authors with fit statistics superior to those reported by Jackson et al. (2009). Miller et al. (2009) stated that factor terms and uniqueness terms were significant but a table is not provided (instead it is available upon request from the first author). Evidence for the predicted four-factor structure of the Social Justice Self-Efficacy subscale was mixed, with reported error indices falling one standard deviation above the mean and the reported fit index above the mean of those reported in Jackson et al., indicating a equivocal fit. No second-order CFA was reported for the subscale. Bivariate correlations between scales of the SIQ met predictions. 
Evidence for the relationships between the SIQ and other variables was limited. Miller et al. (2009) found evidence for divergent validity between a measure of color-blind racial attitudes and the Social Justice Interest and Social Justice Commitment subscales measured -.60 and -.62 , respectively. Evidence for convergent validity was demonstrated with the Social Justice Commitment subscale correlating .22 with a measure of tolerance and acceptance of differences among people. A scale of personal moral imperative correlated moderately with all six SIQ subscales (ranging between .18 and .61) (Miller \& Sendrowitz, 2011). However, the scale is an unpublished three-item scale developed by the authors (Miller \& Sendrowitz, 2008) with no reported procedures for item development or evidence of internal structure. No other relationships between subscales and other variables were reported. Reliability for each scale of the SIQ ranged from good to excellent (Table 1: Ponterotto \& Ruckdeschel, 2007). No testretest reliability was reported.

\section{Social Justice Scale}

The Social Justice Scale (SJS; Torres-Harding, Siers, \& Olson, 2012) is a 24-item scale designed to measure social justice from a blend of community psychology and organizational psychology perspectives. The SJS consists of four subscales which are rated on a Likert-type scale from 1 (disagree strongly) to 7 (strongly agree). The Attitudes Towards Social Justice subscale consists of 11 items (sample item: I believe it is important to allow others to have meaningful input into decisions affecting their lives), the Perceived Behavioral Control subscale has 14 items (sample item: I am certain that I possess an ability to work with individuals and groups in ways that are empowering), the Subjective Norms subscale is comprised of six items (sample item: Other people around me are engaged in activities that address social justice issues), and the Behavioral Intentions subscale has four items (sample item: In the future, I intend to talk with others about social power inequalities, social injustices, and the impact of social forces on health and well-being). In a review of social justice literature in community psychology and counseling psychology, the authors summarize the definitions of social justice as "a value or belief, encompassing the idea that people should have equitable access to resources and protection of human rights . . . and that society should work toward empowerment with people from disadvantaged or disempowered groups" (p. 78). The purpose of the SJS is to better understand how attitudes in social justice lead to social action.

The SJS operationalizes social justice using a social cognitive model developed by Ajzen (1991) that hypothesizes how attitudes translate into behaviors. Behaviors are directly predicted by one's intentions, which in turn are directly predicted by (1) an individual's attitude toward the behavior, (2) the subjective norms of society around that action, and (3) an individual's perceived behavioral control of the action. Torres-Harding et al. (2012) defined social justice attitudes as "an individual's acceptance of the social justice ideals and related values, such as the belief that one should act for social justice, or 
that it is right or fair to promote equality of opportunity for everyone, regardless of background" (p. 79). They defined perceived behavioral control in terms of social justice as "the extent to which a person feels it is possible to 'make a difference,' or the self-evaluation of whether one can have an impact on existing social conditions" ( $p$. 79). Subjective norms in terms of social justice were defined as "the support, or lack thereof, provided in an environment for performing a given behavior" (p. 79).

Item Development. An item-pool was developed for the SJS after a review of the literature that included prominent community psychologists (e.g., Prilleltensky, 2001) and counseling psychologists' (e.g., Constantine et al., 2007; Fouad et al., 2006; Toporek \& Williams, 2006) definitions of social justice. Items were generated to represent a wide content domain of social justice, including the empowerment of people from disadvantaged groups, action to change the distribution of power in society, helping others gain access to societal resources, acknowledging pernicious social inequalities, creating a just community for all, and the belief that all individuals should work towards achieving these goals. Additionally, items were created to fit Ajzen's (1991) social cognitive model described above. A panel with an unspecified number of psychologists and graduate students assessed the face validity, comprehension, and relevance to social justice of each item and made a number of revisions, resulting in a final item pool of 44 items.

Psychometric Evaluation. Evidence for the internal structure of the SJS derives from two studies conducted by Torres et al. (2012). The authors used two CFAs to assess theoretically derived factors. The first CFA used data from 115 graduates and undergraduates and resulted in the elimination of 20 items while the second used a larger pool of 262 graduate and undergraduates. No information was reported on the type of matrix used or the estimation procedure. The resulting 24-item SJS was reanalyzed and demonstrated mixed evidence for fit as the Normed Fit Index and Comparative Fit Index exceeded the mean values reported in Jackson et al. (2009) but the Goodness of Fit Index and Adjusted Goodness of Fit Index fell almost one and a half standard deviations below mean levels reported in Jackson et al. Additionally, the Root Mean Standard Error of Approximation indicated mediocre fit as well. The subscales of the SJS intercorrelated from .34 to .58.

Evidence for the relationship of the SJS subscales with other variables was robust (Torres-Harding et al., 2012). All subscales correlated as predicted, correlating positively with a measure of public service motivation and negatively with a measure of whether people get what they deserve, a measure of subtle racism towards African Americans, and a measure of sexism towards women. Evidence for the criterion validity of the SJS was assessed using a logistic regression and revealed that the Behavioral Intentions subscale predicted engagement in social justice behaviors as reported by participants. Measurement invariance across groups for the SJS was assessed by combining the two samples and comparing different demographic categories. Results indicated no difference in responding in terms of gender, age, or race. However, 
people with a disability obtained higher scores on the Behavioral Intentions subscale than people without a disability.

As Table 1 illustrates, internal consistency coefficients of the SJS subscales fell in the excellent range (Ponterotto \& Ruckdeschel, 2007). No test-retest reliability data was reported.

\section{Discussion and Recommendations}

We have reviewed in depth four instruments used to measure social justice advocacy: the AOS (Corning \& Myers, 2002), the SIAS (Nilsson et al., 2011), the SIQ (Miller et al., 2009), and the SJS (Torres-Harding et al., 2012). A summary of each instrument's psychometric properties and limitations is provided in Table 1 . Of the four reviewed scales, the AOS provides a direct, relatively brief measure of political activist attitudes validated on community samples and demonstrating evidence of criterion validity. Practitioners interested in a direct evaluation of an individual's willingness to engage in protest behavior should first consider the AOS. The SIAS offers a brief, thoughtfully constructed measure of general social justice and advocacy attitudes with strong evidence for its internal structure. In practice it provides a unique assessment towards an individual's willingness to confront discrimination. The SIQ presents a longer measure assessing social justice commitment and interest using a social cognitive framework and is distinctive in presenting evidence for its hypothesized causal structure of social justice commitment. Practitioners may find it useful in identifying barriers to an individual's social justice engagement. The SJS provides a brief measure of social justice attitudes based on an alternative social cognitive framework and was the sole instrument offering preliminary evidence of its invariance across populations. It offers practitioners a promising tool to predict engagement in social justice behavior from an individual's attitudes.

All four instruments share similar limitations. First, all four measures require evidence of test-retest reliability. Although the selected scales are based on constructs predicted to be stable across time (e.g., attitudes), there is no evidence presented that this is in fact the case. Second, although all fours scales demonstrated relatively strong initial evidence for their proposed internal structures, using alternative analytic methods would increase confidence in these putative structures. For instance, for the AOS, using confirmatory factor analytic methods on a different sample would increase confidence in the proposed two-factor model. For the SJS, use of exploratory factor analytic methods would strengthen the evidence that the 44 SJS items load onto their parent factors as predicted by the authors, especially given the equivocal CFA indices presented in Torres-Harding et al. (2012). Third, only one scale, the AOS, provided evidence that it predicts actual behavior (Corning \& Myers, 2002). Further evidence of the predictive validity of the AOS and initial evidence for the other scales is needed. 
Finally, the samples on which the scales were developed were homogeneous in terms of demographics, with all scales being validated on samples of primarily White students in post-secondary education, and with three of the four scales having predominantly female samples. It is difficult to find diverse samples large enough for validity studies, yet there appears to be a philosophical inconsistency in creating a scale for social justice that does not include those populations most impacted by societal inequity. By not including significant representation from these communities, we risk unintentionally silencing their voices and furthering institutional power structures with our beneficial intentions. For instance, development of the Confronting Discrimination subscale for the SIAS resulted in a three-item scale. Each item addressed speaking out against discrimination towards one facet of identity: either the elderly, individuals with disability, or people from disadvantaged ethnic/cultural groups. It remains unclear whether the initial 96 items developed for the SIAS addressed other areas of identity oppression (e.g., sexual orientation, gender, religion, socioeconomic status). If so, one wonders whether factor analysis of a more heterogeneous, broadly representative sample would have retained items that reflected different identity characteristics in addition to (or perhaps instead of) those selected for the current scale. As the scale now stands, a researcher using it will unintentionally exclude some groups from inclusion in assessments of confronting discrimination. If social justice and advocacy are about representation of unheard voices, then the scale ironically reinforces the very power structures the authors intended the scale to address. This is problematic for each scale reviewed in this article.

Moreover, it is not so simple as to merely administer our instruments to more diverse populations and include them in the analysis. As eloquently demonstrated by Hill, Robbins, and Pace (2010) in their mixed-methods analysis of East Woodlands Nation peoples taking the Minnesota Multiphasic Personality Inventory-2, reliance on analytic methods at the expense of understanding why certain items are endorsed by specific populations in particular ways risks significant misinterpretation of the results. As researchers of social justice, we must demonstrate an increased sensitivity to any guilt, unidentified privilege, or lack of experience with different forms of oppression which we may bring to our research. To lose sight of this risks serious confound of research results and furthering oppressive power structures for other groups. Although there may be a place for quantitative research in furthering our understanding of social justice (see Cokley \& Awad, 2013), it requires supplementation by other analytic methods and care in the way in which it is implemented.

\section{Future Directions for Social Justice and Advocacy Research}

The unique qualities of the AOS, SIAS, SIQ, and SJS sanction their use as foundations for future research. One such line of research may be individual differences in social justice engagement behavior. Conceptualization of social justice assessment may change if broad traits such as extraversion, conscientiousness, or openness to 
experience were to predict social justice involvement. It would be valuable to compare constructs about social justice and advocacy to similar constructs developed in other disciplines, such as justice sensitivity (Schmitt, Baumert, Gollwitzer, \& Maes, 2010), altruism (Schroeder, Dovidio, Penner, \& Piliavin, 1994), belief in a just world (Rubin \& Peplau, 1975) or organizational justice (Colquitt, 2001). Overlap between these constructs may provide useful insights into theories about human behavior regarding fairness and advocating on behalf of others.

Another valuable line of research would be to examine discrepancies among mental health professionals in their approach to social justice. This seems particularly important given the need for multicultural competence in therapeutic practice and the disparities found for services received by different cultural groups (Speight \& Vera, 2008). Examining why professionals advocate for some groups but not for others or why some groups remain neglected in mental health service may provide further insight into addressing these discrepancies and providing more equitable treatment for all.

Future research could address the mono-method bias inherent in using only self-report instruments to assess social justice and advocacy. Given that social justice and advocacy are among the few constructs in social science that can be defined and measured by clearly observable behavior, it is important that alternative measurement of assessment be developed to further expand upon our knowledge base and to more accurately assess social justice and advocacy behaviors.

Disadvantaged groups in society confront numerous barriers which perpetuate entrenched power structures and result in penurious physical and psychological effects. It is important to remember that research in social justice and advocacy can reinforce these inequitable social structures as much as it can change them. It is our hope that the instruments reviewed in this article can be used to better understand how social justice and advocacy can be promoted in a way which helps all groups in society.

Note: The authors wish to thank the reviewers from the Journal for Social Action in Counseling and Psychology and specifically the one reviewer who highlighted the philosophical inconsistencies inherent in the scales.

\section{Author contact information}

Alexander W. Fietzer, Department of Educational Foundations and Counseling, School of Education, Hunter College of the City University of New York, New York, NY 10128. Email: af1173@hunter.cuny.edu 
Volume 7, Number 1, Summer 2015

\section{References}

Almeida, J., Johnson, R. M., Corliss, H. L., Molnar, B. E., \& Azrael, D. (2009). Emotional distress among LGBT youth: The influence of perceived discrimination based on sexual orientation. Journal of Youth and Adolescence, 38, 1001-1014. doi: 10.1007/s10964-009-9397-9

American Educational Research Association, American Psychological Association, National Council on Measurement in Education. (1999). Standards for educational and psychological testing. Washington, DC: American Educational Research Association.

Ajzen, I. (1991). The theory of planned behavior. Organizational Behavior and Human Decision Processes, 50, 179-211.

Barnes, L. L., Mendes de Leon, C. F., Lewis, T. T., Bienias, J. L., Wilson, R. S., \& Evans, D. A. (2008). Perceived discrimination and mortality in a population-based study of older adults. American Journal of Public Health, 98, 1241-1247. doi: 10.2105/AJPH.2007.114397

Beer, A. M., Spanierman, L. B., Greene, J. C., \& Todd, N. R. (2012). Counseling psychology trainees' perceptions of training and commitments to social justice. Journal of Counseling Psychology, 59, 120-133. doi: 10.1037/a0026325

Broido, E. M. (2000). The development of social justice allies during college: A phenomenological investigation. Journal of College Student Development, 41, 318.

Byrne, B. M. (2010). Structural equation modeling with AMOS: Basic concepts, applications, and programming (2nd ed.). New York: Routledge.

Chang, C. Y., Crethar, H. C., \& Ratts, M. J. (2010). Social justice: A national imperative for counselor education and supervision. Counselor Education \& Supervision, 50, 82-87. doi: 10.1002/j.1556-6978.2010.tb00110.x

Clark, L., \& Watson, D. (1995). Constructing validity: Basic issues in objective scale development. Psychological Assessment, 7, 309-319.

Cokley, K., \& Awad, G. (2013). In defense of quantitative methods: Using the "master's tools" to promote social justice. The Journal for Social Action in Counseling and Psychology, 5(2), 26-41.

Colquitt, J. A. (2001). On the dimensionality of organizational justice: A construct validation of a measure. Journal of Applied Psychology, 86, 386-400. 
Constantine, M. G., Hage, S. M., Kindaichi, M. M., \& Bryant, R. M. (2007). Social justice and multicultural issues: Implications for the practice and training of counselors and counseling psychologists. Journal of Counseling \& Development, 85, 24-29. doi: 10.1002/j.1556-6678.2007.tb00440.x

Corning, A. F., \& Myers, D. J. (2002). Individual orientation toward engagement in social action. Political Psychology, 23, 703-729. doi: 10.1111/0162-895X.00304

Crethar, H. C., Torres Rivera, E., \& Nash, S. (2008). In search of common threads: Linking multicultural, feminist, and social justice counseling paradigms. Journal of Counseling and Development, 86, 269-278. doi: 10.1002/j.15566678.2008.tb00509.x

Dean, J. K. (2009). Quantifying social justice advocacy competency: Development of the social justice advocacy scale. Dissertation Abstracts International Section A: Humanities and Social Sciences, 69 (12-A), 4638.

Fabrigar, L. R., Wegener, D. T., MacCallum, R. C., \& Strahan, E. J. (1999). Evaluating the use of exploratory factor analysis in psychological research. Psychological Methods, 4, 272-299. doi: 10.1037/1082-989X.4.3.272

Fouad, N., Gerstein, L., \& Toporek, R. (2006). Social justice and counseling psychology in context. In R. L. Toporek, L. H. Gerstein, N. A. Fouad, G. Roysicar, \& T. Israel (Eds.), Handbook for social justice in counseling psychology (pp. 2-17). Thousand Oaks, CA: Sage. doi: 10.4135/978-1-41297-622-0.n1

Furr, R. M., \& Bacharach, V. R. (2008). Psychometrics: An introduction. Thousand Oaks, CA: Sage Publications.

Gehlbach, H., \& Brinkworth, M. E. (2011). Measure twice, cut down error: A process for enhancing the validity of survey scales. Review of General Psychology, 15, 380-387. doi: 10.1037/a0025704

Goodman, L. A., Liang, B., Helms, J. E., Latta, R. E., Sparks, E., \& Weintraub, S. R. (2004). Training counseling psychologists as social justice agents: Feminist and multicultural principles in action. The Counseling Psychologist, 32, 793-837. doi: $10.1177 / 0011000004268802$

Hill, J. S., Pace, T. M., \& Robbins, R. R. (2010). Decolonizing personality assessment and honoring indigenous voices: A critical examination of the MMPI-2. Cultural Diversity and Ethnic Minority Psychology, 16, 16-25. doi: 10.1037/a0016110 
Hunte, H. E. R., \& Williams, D. R. (2009). The association between perceived discrimination and obesity in a population-based multiracial and multiethnic adult sample. American Journal of Public Health, 99, 1285-1292.

Jackson, D. L., Gillaspy, J. A., Jr., Purc-Stephenson, R. (2009). Reporting practices in confirmatory factor analysis: An overview and some recommendations. Psychological Methods, 14, 6-23. doi: 10.1037/a0014694

Klar, M., \& Kasser, T. (2009). Some benefits of being an activist: Measuring activism and its role in psychological well-being. Political Psychology, 30, 755-777. doi:10.1111/j.1467-9221.2009.00724.x

Lent, R. W., Brown, S. D., Brenner, B., Chopra, S. B., Davis, T., Tallyrand, R., et al. (2001). The role of contextual supports and barriers in the choice of math/science educational options: A test of social cognitive hypotheses. Journal of Counseling Psychology, 48, 474-483. doi: 10.1037/0022-0167.48.4.474

Lent, R. W., Brown, S. D., \& Hackett, G. (1994). Toward a unifying social cognitive theory of career and academic interest, choice, and performance [Monograph]. Journal of Vocational Behavior, 45, 79-122. doi:10.1006/jvbe.1994.1027

Lewis, J. A., Arnold, M. S., House, R., \& Toporek, R. L. (2002). ACA advocacy competencies. Retrieved November 25th, 2012, from http://www.counseling.org/Publications/

MacCallum, R. C., Widaman, K. F., Zhang, S., \& Hong, S. (1999). Sample size in factor analysis. Psychological Methods, 4, 84-99. doi: 10.1037/1082-989X.4.1.84

Miller, M. J., \& Sendrowitz, K. (2008). Validating the SIQ in a community sample. Unpublished manuscript.

Miller, M. J., \& Sendrowitz, K. (2011). Counseling psychology trainees' social justice interest and commitment. Journal of Counseling Psychology, 58, 159-169. doi: $10.1037 / \mathrm{a} 0022663$

Miller, M. J., Sendrowitz, K., Connacher, C., Blanco, S., Muñiz de la Peña, C., Bernardi, S., \& Moere, L. (2009). College students' social justice interest and commitment: A social-cognitive perspective. Journal of Counseling Psychology, 56, 495-507. doi: 10.1037/a0017220

Miller, M. J., Sendrowitz, K., Connacher, C., Blanco, S., Muñiz de la Peña, C., Morere, L., \& Bernardi, S. (2007). Development of the SIQ. Unpublished manuscript. 
Nilsson, J. E., Marszalek, J. M., Linnemeyer, R. M., Bahner, A. D., \& Misialek, L. H. (2011). Development and assessment of the Social Issues Advocacy Scale. Educational and Psychological Measurement, 71, 258-275. doi: $10.1177 / 0013164410391581$

Nilsson, J. E., \& Schmidt, C. K. (2005). Social justice advocacy among graduate students in counseling: An initial exploration. Journal of College Student Development, 46, 267-279. doi: 10.1353/csd.2005.0030

O'Connor, B. P. (2000). SPSS and SAS programs for determining the number of components using parallel analysis and Velicer's MAP test. Behavior Research Methods, Instrumentation, and Computers, 32, 396-402.

Osborne, J. W., \& Fitzpatrick, D. C. (2012). Replication analysis in exploratory factor analysis: What it is and why it makes your analysis better. Practical Assessment, Research \& Evaluation, 17(15). Available online: http://pareonline.net/getvn.asp?v=17\&n=15.

Pascoe, E. A., \& Richman, L. S. (2009). Perceived discrimination and health: A metaanalytic review. Psychological Bulletin, 135, 531-554. doi: 10.1037/a0016059

Peach, J. M., Yoshida, E., Spencer, S. J., Zanna, M. P., \& Steele, J. R. (2011). Recognizing discrimination explicitly while denying it implicitly: Implicit social identity protection. Journal of Experimental Social Psychology, 47, 283-292. doi: 10.1016/j.jesp.2010.09.007

Pieterse, A. L., Evans, S. A., Risner-Butner, A., Collins, N. M., \& Mason, L. B. (2009). Multicultural competence and social justice training in counseling psychology and counselor education: A review and analysis of a sample of multicultural course syllabi. The Counseling Psychologist, 37, 93-115. doi: $10.1177 / 0011000008319986$

Ponterotto, J. G., \& Ruckdeschel, D. E. (2007). An overview of coefficient alpha and a reliability matrix for estimating adequacy of internal consistency coefficients with psychological research measures. Perceptual and Motor Skills, 105, 997-1014. doi: $10.2466 / p m s .105 .3 .997-1014$

Prilleltensky, I. (2001). Value-based praxis in community psychology: Moving towards social justice and social action. American Journal of Community Psychology, 29(5), 747-778. doi: 10.1023/A:1010417201918

Prior, M. K., \& Quinn, A. S. (2012). The relationship between spirituality and social justice advocacy: Attitudes of social work students. Journal of Religion \& 
Spirituality in Social Work: Social Thought, 31, 172-192. doi: 10.1080/15426432.2012.647965

Rawls, J. (1971). A theory of justice. Cambridge, MA: Harvard University Press.

Raykov, T., \& Marcoulides, G. A. (2006). A first course in structural equation modeling (2nd ed.). Mahwah, NJ: Lawrence Erlbaum Associates, Inc.

Rubin, Z., \& Peplau, L. A. (1975). Who believes in a just world? Journal of Social Issues, 31, 65-90.

Ruscio, J., \& Roche, B. (2012). Determining the number of factors to retain in an exploratory factor analysis using comparison data of known factorial structure. Psychological Assessment, 24, 282-292. doi: 10.1037/a0025697

Schmitt, M., Baumert, A., Gollwitzer, M., \& Maes, J. (2010). The Justice Sensitivity Inventory: Factorial Validity, location in personality space, demographic pattern, and normative data. Social Justice Research, 23, 211-238. doi: $10.1007 / \mathrm{s} 11211-010-0115-2$

Schroeder, D. A., Dovidio, J. F., Penner, L. A., Piliavin, J. A. (1994). The social psychology of helping and altruism: Problems and puzzles. New York: McGrawHill.

Speight, S. L., \& Vera, E. M. (2008). Social justice and counseling psychology: A challenge to the profession. In S. D. Brown \& R. W. Lent (Eds.) Handbook of counseling psychology (4th ed., pp. 54-67). Hoboken, NJ: John Wiley \& Sons.

Torres-Harding, S. R., Carollo, O., Schamberger, A., \& Clifton-Soderstrom, K. (2013). Values and religiosity as predictors of engagement in social justice. Journal of Prevention \& Intervention in the Community, 41(4), 255-266. doi: $10.1080 / 10852352.2013 .818489$

Torres-Harding, S. R., Siers, B., \& Olson, B. D. (2012). Development and psychometric evaluation of the Social Justice Scale (SJS). American Journal of Community Psychology, 50, 77-88. doi: 10.1007/s10464-011-9478-2

Vera, E. M., \& Speight, S. L. (2003). Multicultural competence, social justice, and counseling psychology: Expanding our roles. The Counseling Psychologist, 31, 253-272. doi: 10.1177/0011000003031003001

Worthington, R. L., \& Whittaker, T. A. (2006). Scale development research: A content analysis and recommendations for best practices. The Counseling Psychologist, 34, 806-838. doi: 10.1177/0011000006288127 


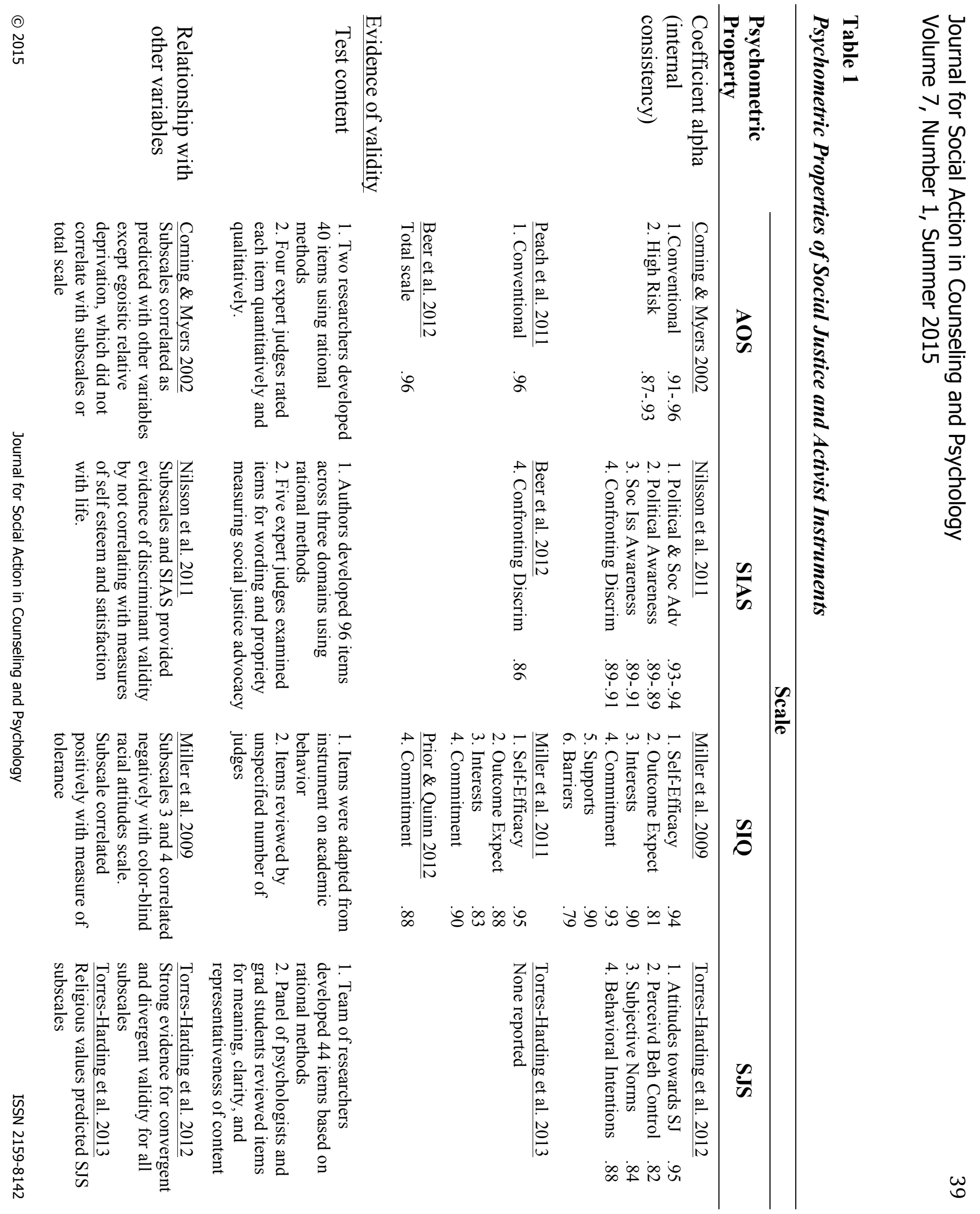




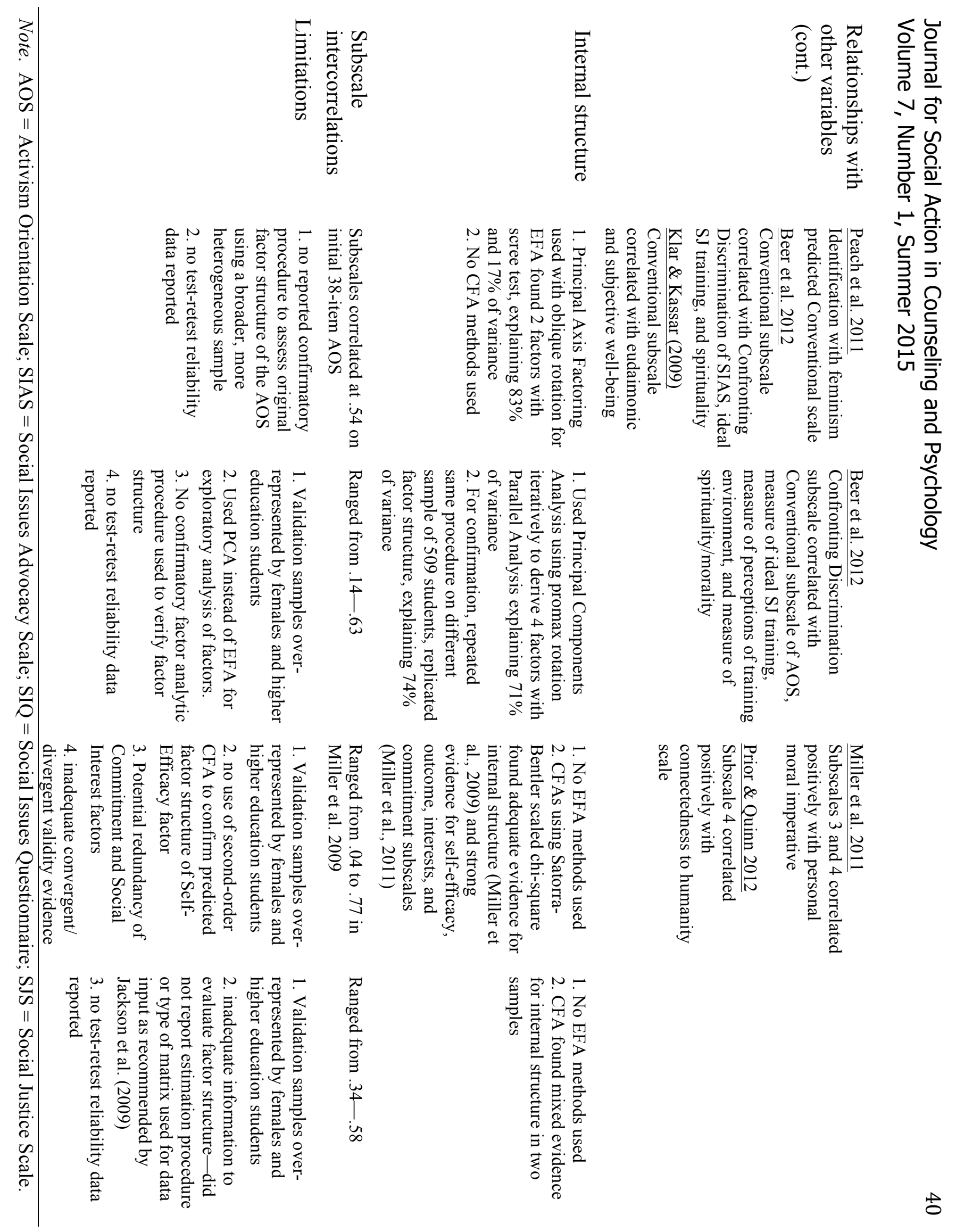

